\title{
DEVELOPING GROUP LEADERSHIP AND COMMUNICATION SKILLS FOR MONITORING EVM IN PROJECT MANAGEMENT
}

\author{
G.M.G Farok ${ }^{1,2, *}$ and Jose A. Garcia ${ }^{2,{ }^{, * *}}$ \\ 'Dhaka Water Supply and Sewerage Authority, Bangladesh \\ ${ }^{2}$ Ryerson University, Toronto, Canada. \\ Corresponding e-mail: gazi.farok@yahoo.com*, jose1.garcia@ryerson.ca**
}

\begin{abstract}
Earned Value Management (EVM) is used to track the progress and status of a project with forecasting future performance. Leaders use the Evaluation, Verification and Monitoring with Earned Value Management (EVM) technique to evaluate their project progress and performance as an 'early warning tool'. Monitoring EVM involves determining whether the project is on, ahead of, or behind schedule and on, under or over budget. Usually an organization has many people with many multi-dimensional strategic ideas. All of these people are focused on ultimate end points, they work on the same target, they play on the same field, and they gain their knowledge about the same markets and share their ideas with personal confident. They rely on EVM which integrates cost, schedule and scope to capture project progress assessment and project completion update.
\end{abstract}

Keywords: EVM, Leadership, Communication, Stakeholder, Monitoring.

\section{INTRODUCTION}

EVM provides technical, schedule, cost performance auditable information against the project baseline plan for proactive leadership actions. A great leader needs to be an effective communicator. Leadership and communication are considered like soft skills. Global market place demands compliment between soft skill and hard skill. Soft skills include cluster of personal traits and habits, language conversations, social graces, optimism and friendship relations. Leadership and communication lead the professional people by actualization of bottom line improvements, balancing competition and absorbing globalization. Harvard Business professor and author John Kotter stated that leadership produces change and it is the primary function. Leaders must set the directions for change and this change is not similar to planning $^{1}$. Leadership also involves risk and change. The leader's function is to implement the right direction for change. The situation in which organizations operate can change all of a sudden. Leaders help to create an attitude for an organization that expects change and is willing to adapt. Leaders should encourage an environment that promotes constant innovation. Organizations that accept change are more likely to stay ahead of the race. Internal change in an organization is essential; if a change is welcomed in the global system. Organizational structure is an enterprise environmental factor that influences a project. Organizational structures are six types: i) Functional organization, ii) Weak matrix organization, iii) Balanced matrix organization, iv) Strong matrix organization, v) Projectized organization, vi) Composite organization ${ }^{2}$.

Project management research on the contribution of EVM to project success suggests a moderately strong positive relationship ${ }^{3,4,5}$. Considering 'Cost Management Technique', indirect costs lead to overhead items or costs incurred for the benefit of more than one project like taxes, fringe benefits etc. Contingency reserve is developed for the risks remaining after risk response planning. Management reserve is any extra amount of funds to be set aside to cover unforeseen risks or changes to the project ${ }^{6}$. This study focuses on the structure of the project organization, accountability, responsibility, communication as well as a review of the project management literature on sociological, technological, economic, ethical, political, legal and environmental aspects. The analytical and mathematical findings confirmed that visionary leadership is about achievable goals, initiating action and enlisting the participation of others. It also developed a model for EVM and compared its characteristic curves for project management activities. This research obtained plan, organize and control activities in such a way that risks are avoided or countered leading to a final result by numerical case studies. It would satisfy the requirements of the project sponsor without using more money and resources than those which were included in the budget.

\section{LEADERSHIP IN PROJECT MANAGEMENT}

Leaders are individuals whom implement the concepts of vision, mission, values and change. Leaders have their apparently thinking of abilities with a lot of ideas but use to motivate as one person single brain. For the project team, professional and social responsibilities have four categories: responsibility, respect, fairness and honesty? The project manager should maintain five interpersonal skills: i) Leadership, ii) Team building, 
iii) Motivation, iv) Communication, and v) Influencing ${ }^{8}$. Project Management is affected by related disciplines and in return, it influences them ${ }^{9}$. Project is an organization of people dedicated to a specific purpose or objective. Projects generally involve large, expensive, unique or high risk undertakings which have to be completed by a certain date, for a certain amount of money, within some expected level of performance ${ }^{10}$. Project Management in Engineering Professionals has shifted. Since an around a decade ago, what it means to be a wellprepared engineer in the 21 st century has shifted with quickly evolving technology and the global economy have increased demand for engineering professionals who can work in teams to solve complex problems. This requires understanding engineering design and practice. For technical skills, the Accreditation Board for Engineering and Technology (ABET) has stressed that engineering students learn professional skills such as teamwork and communication to be well rounded problem-solvers ${ }^{11}$. Research on Project Management in the Education industry indicate that higher education institutions, universities need to provide project management education and role-play training to form an appropriate tool for universities as an efficient alternative to on-the-job training for project management education $^{12}$. EVM emerged as a financial analysis specialty in USA Government schedules and programs in the 1960s, but it has since become a significant branch of project management and cost engineering. EVM is designed and implemented to maximize significant benefits for project stakeholders.

\section{IMPORTANCE OF PROJECT COMMUNICATIONS}

Usually communication demonstrates how information is sent and received between two parties, defined as the sender and the receiver. The key components of the model include: i) Encode- to translate thoughts or ideas into a language that is understood by others, ii) Message and feedbackmessage- the output of encoding, iii) Medium- the method used to convey the message, iv) Noiseanything that interferes with the transmission and understanding of the message (e.g., distance, unfamiliar technology, lack of background information), v) Decode- to translate the message back into meaningful thoughts or ideas.

$$
\text { Number of Communiction channels }=\frac{\mathrm{N}(\mathrm{N}-1)}{2} \quad \mathrm{~N}=\text { Number of Project Team Members. }
$$

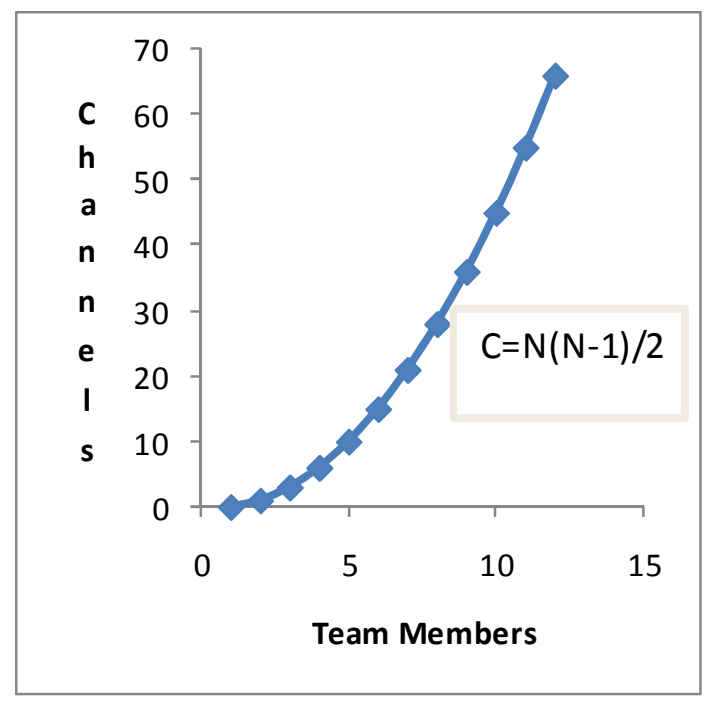

Figure 1. Communications Channels vs. Team Members.

This is a communication model ${ }^{2}$ and this model is an action to acknowledge a message. Acknowledgement means that the receiver signals receipt of the message, but not necessarily agreement with the message. Another action is the response to a message, which means that the receiver has decoded, understands, and is replying to the message. The components in the communications model need to be taken into account when discussing project communications. For the communications process, the sender is responsible for making the information clear and complete so that the receiver can receive it correctly, and for confirming that it is properly understood. The receiver is responsible for making sure that the information is received in its entirety, understood correctly, and acknowledged. A failure in communication can negatively impact the project. There are many challenges in using these components to effectively communicate with project stakeholders (Figure 1). Consider a highly technical, multinational project team. For one team member to successfully communicate a technical concept to another team 
member in a different country can involve encoding the message in the appropriate language, sending the message using a variety of technologies, and having the receiver decode the message and reply or provide feedback. Any noise introduced along the way compromises the original meaning of the message. The couple of communication methods used to share information among project stakeholders. The communication methods have three classifications: i) Interactive communication: Between two or more parties performing a multidirectional exchange of information. It is the most efficient way to ensure a common understanding by all participants on specified topics, and includes meetings, phone calls, video conferencing, etc.

ii) Push communication: Sent to specific recipients who need to know the information. This ensures that the information is distributed but does not certify that it actually reached or was understood by the intended audience. Push communication includes letters, memos, reports, emails, faxes, voice mails, press releases etc.

iii) Pull communication: Useful for very large volumes of information, or for very large audiences, that requires the recipients to access the communication content at their own discretion. These methods include intranet sites, e-learning, and knowledge repositories, etc. The project manager decides, based on communication requirements, what, how, and when communication methods are to be used in the project.

\section{EVM PARAMETERS}

Planned value (PV) is the authorized budget assigned to the work to be accomplished for an activity or work breakdown structure component. It includes the detailed authorized work, plus the budget for such authorized work, allocated by phase over the life of the project. The total of the PV is sometimes referred to as the performance measurement baseline (PMB). The total planned value for the project is also known as Budget At Completion (BAC). Earned value $(E V)$ is the value of work performed expressed by the approved budget assigned to that work for an activity or work breakdown structure component. It is the authorized work that has been completed, plus the authorized budget for such completed work. Actual cost (AC) is the total cost actually incurred in accomplishing work performed according to WBS and an activity. It is the money which project manager spent to date. EVM has five sections: i) Organization, ii) Planning, scheduling, budgeting, iii) Accounting considerations, iv) Analysis and Management reports, v) Revision and data maintenance. EVM improves planning process, fosters a clear idea of scope of work, confirms responsibility for work effort, analyze early warning of potential problems, integrates triple constraints of a project, identifies problem to take immediate management action, provides project visibility and accountability with risk factors at all management level ${ }^{14}$.

\section{EVM Techniques}

The earned value management (EVM) technique was developed by the US Department of Defense in the 1960s as an alternative to the PERT methodology. It began to spread into the corporate world in the $1980 \mathrm{~s}^{13}$. Traditional definitions of EVM typically assume that project accounting and project network schedule management are prerequisites to achieving any benefit from EVM. Many small projects don't satisfy either of these prerequisites, but they too can benefit from EVM, as described for simple implementations, above. Other projects can be planned with a project network, but do not have access to true and timely actual cost data. In practice, the collection of true and timely actual cost data can be the most difficult aspect of EVM. Such projects can benefit from EVM, as described for intermediate implementations, above, and Earned Schedule. EVM is the control tool used for cost control and it is one of the most important areas in project management. It also provides additional useful information for the schedule variance. When used with progress reporting to determine schedule variance and schedule performance index, EVM becomes a highly valuable tool to track both cost and schedule. As a means of overcoming objections to EVM's lack of connection to qualitative performance issues, the Naval Air Systems Command organization initiated a project in the late 1990s to integrate true technical achievement into EVM projections by utilizing risk profiles. These risk profiles anticipate opportunities that may be revealed and possibly be exploited as development and testing proceeds. The research was peer-reviewed and was the recipient of the Defense Acquisition University Acquisition Research Symposium 1997 Acker Award for excellence in the exchange of information in the field of acquisition research. The published research resulted in a Technical Performance Management (TPM) methodology and software application that is still used by many agencies in informing EVM estimates with technical achievement ${ }^{15}$.

\section{Modeling with EVM Parameters}

The EV being measured must be related to the PV baseline (PMB), and the EV measured cannot be greater than the authorized $\mathrm{PV}$ budget for a component.

$$
\mathrm{PV}=\frac{\mathrm{FV}}{\left(1+\frac{\mathrm{r}}{100}\right)^{\mathrm{n}}}
$$

where, $r=$ Rate of Interest, $\mathrm{n}=$ No of Years, $\mathrm{PV}=$ Present Value, FV = Future Value.

The term EV is often used to describe the percentage completion of a project. Progress measurement 
criteria should be established for each work break structure component to measure work in progress. Project managers monitor EV, both incrementally to determine current status and cumulatively to determine the long-term performance trends. Actual cost (AC) is the total cost actually incurred and recorded in accomplishing work performed for an activity or work breakdown structure component. It is the total cost incurred in accomplishing the work that the EV measured. The $\mathrm{AC}$ has to correspond in definition to whatever was budgeted for in the PV and measured in the EV (e.g., direct hours only, direct costs only, or all costs including indirect costs). The $\mathrm{AC}$ will have no upper limit; whatever is spent to achieve the EV will be measured. Variances from the approved baseline will also be monitored.

Schedule variance (SV) is a measure of schedule performance on a project. It is equal to the earned value $(\mathrm{EV})$ minus the planned value (PV). The EVM schedule variance is a useful metric in that it can indicate a project falling behind its baseline schedule. The EVM schedule variance will ultimately equal zero when the project is completed because all of the planned values will have been earned. The SV at EVM is the best used in conjunction with critical path methodology (CPM) scheduling and risk management by following equation:

$$
\mathrm{SV}=\mathrm{EV}-\mathrm{PV}
$$

Cost variance $(\mathrm{CV})$ is a measure of cost performance on a project. It is equal to the earned value (EV) minus the actual costs (AC). The cost variance at the end of the project will be the difference between the budget at completion (BAC) and the actual amount spent. The CV at EVM is particularly critical because it indicates the relationship of physical performance to the costs spent. Any negative CV at EVM is often non-recoverable to the project and $\mathrm{CV}$ is derived with following equation:

$$
\mathrm{CV}=\mathrm{EV}-\mathrm{AC}
$$

The SV and CV values can be converted to efficiency indicators to explain the cost and schedule performance of any project for comparison against all other projects or within a portfolio of projects. The variances and indices are useful for determining project status and providing a basis for estimating project cost and schedule outcome.

The schedule performance index (SPI) is a measure of progress achieved compared to progress planned on a project. It is sometimes used in conjunction with the cost performance index (CPI) to forecast the final project completion estimates. An SPI value less than 1.0 indicates less work was completed than was planned. An SPI greater than 1.0 indicates that more work was completed than was planned. Since the SPI measures all project work, the performance on the critical path might be analyzed to determine whether the project will be finished ahead of or behind its planned finished date. The SPI is equal to the ratio of the $\mathrm{EV}$ to the $\mathrm{PV}$ with following equation:

$$
\mathrm{SPI}=\frac{\mathrm{EV}}{\mathrm{PV}}
$$

The cost performance index (CPI) is a measure of the value of work completed compared to the actual cost or progress made on the project. It is considered the most critical EVM metric and measures the cost efficiency for the work completed. A CPI value less than 1.0 indicates a cost overrun for work completed. A CPI value greater than 1.0 indicates a cost under run of performance to date. The CPI is equal to the ratio of the EV to the AC. Equation:

$$
\mathrm{CPI}=\frac{\mathrm{EV}}{\mathrm{AC}}
$$

The three parameters of PV, EV, and AC can be monitored and reported on both a period-by-period basis (typically weekly or monthly) and on a cumulative basis. Forecasts are generated, updated, and reissued based on work performance information provided as the project is executed. The work performance information covers the project past performance and any information that could impact the project in the future. EACs are typically based on the actual costs incurred for work completed, plus an estimate to complete (ETC) the remaining work. It is incumbent on the project team to predict what it may encounter to perform the ETC, based on its experience to date. The EVM method works well in conjunction with manual forecasts of the required EAC costs. The most common EAC forecasting approach is a manual, bottom-up summation by the project manager and project team. The project manager's bottom-up EAC method builds upon the actual costs and experience incurred for the work completed, and requires a new estimate to complete the remaining project work. This method may be problematic in that it interferes with the conduct of project work. The personnel who are performing the project work have to stop working to provide a detailed bottom-up ETC of the remaining work. Typically there is no separate budget to perform the ETC, so additional costs are incurred for the project to conduct the ETC. Equation: $\mathrm{EAC}=\mathrm{AC}+$ bottom-up ETC. The project manager's manual EAC can be quickly compared with a range of calculated EACs representing various risk scenarios. While EVM data can quickly provide many statistical EACs, only three of the more common methods are described as follows:

If variances are atypical,

$$
\mathrm{EAC}=\mathrm{AC}+\mathrm{BAC}-\mathrm{EV}
$$


EAC forecast for ETC work performed at the budgeted rate. This EAC method accepts the actual project performance to date (whether favourable or unfavourable) as represented by the actual costs, and predicts that all future ETC work will be accomplished at the budgeted rate. As the project progresses, the project team can develop a forecast for the estimate at completion (EAC) that may differ from the budget at completion (BAC) based on the project performance. If it becomes obvious that the $\mathrm{BAC}$ is no longer viable, the project manager should develop a forecasted EAC. Forecasting the EAC involves making estimates or predictions of conditions and events in the project's future based on information and knowledge available at the time of the forecast. When actual performance is unfavourable, the assumption that future performance will improve should be accepted only when supported by project risk analysis. Equation (for a new estimate):

$$
\mathrm{ETC}=\mathrm{EAC}-\mathrm{AC}
$$

EAC forecast for ETC work performed at the present CPI. This method assumes what the project has experienced to date can be expected to continue in the future. The ETC work is assumed to be performed at the same cumulative cost performance index (CPI) as that incurred by the project to date. The following managerial equation for variance at completion (VAC) (When variances are typical):

$$
\begin{gathered}
\mathrm{EAC}=\mathrm{AC}+\frac{\mathrm{BAC}-\mathrm{EV}}{\mathrm{CPI}}=\frac{\mathrm{BAC}}{\mathrm{CPI}} \\
\mathrm{VAC}=\mathrm{BAC}-\mathrm{EAC}
\end{gathered}
$$

EAC forecast for ETC work considering both SPI and CPI factors. In this forecast, the ETC work will be performed at an efficiency rate that considers both the cost and schedule performance indices. It assumes both a negative cost performance to date, and a requirement to meet a firm schedule commitment by the project. This method is most useful when the project schedule is a factor impacting the ETC effort. Variations of this method weigh the CPI and SPI at different values (e.g., 80/20, 50/50, or some other ratio) according to the project manager's judgment with the following equation:

$$
\mathrm{EAC}=\mathrm{AC}+\frac{\mathrm{BAC}-\mathrm{EV}}{\text { cumulative } \mathrm{CPI} * \text { cumulative SPI }}
$$

Each of these approaches can be correct for any given project and will provide the project management team with an "early warning" signal if the EAC forecasts are not within acceptable tolerances.

The to-complete performance index (TCPI) is the calculated projection of cost performance that must be achieved on the remaining work to meet a specified management goal, such as the BAC or the EAC. If it becomes obvious that the $\mathrm{BAC}$ is no longer viable, the project manager develops a forecasted estimate at completion (EAC). Once approved, the EAC effectively supersedes the BAC as the cost performance goal. Equation for the TCPI based on the BAC:

$$
\mathrm{TCPI}_{\mathrm{BAC}}=\frac{\mathrm{BAC}-\mathrm{EV}}{\mathrm{BAC}-\mathrm{AC}}
$$

The TCPI is the ratio of the work remaining (BAC $\mathrm{EV}$ ) divided by the funds remaining (BAC- $\mathrm{AC}$ or EAC - AC). If the cumulative CPI falls below the baseline plan, all future work of the project will need to immediately be performed in the range of the TCPI (BAC) to stay within the authorized BAC. Whether this level of performance is achievable is a judgment call based on a number of considerations, including risks, schedule, and technical performance. Once management acknowledges that the BAC is no longer attainable, the project manager will prepare a new estimate at completion (EAC) for the work, and once approved, the project will work to the new EAC value. This level of performance is displayed as the TCPI (EAC) line. The equation for the TCPI based on the EAC:

$$
\mathrm{TCPI}_{\mathrm{EAC}}=\frac{\mathrm{BAC}-\mathrm{EV}}{\mathrm{EAC}-\mathrm{AC}}
$$

Performance reviews compare cost performance over time, schedule activities or work packages overrunning and under running the budget, and estimated funds needed to complete work in progress. If EVM is being used, the Independent estimate at completion (IEAC) is used and IEAC is a metric to project total cost using the performance to date to project overall performance. In addition, EAC is the manager's projection.

$$
\mathrm{IEAC}=\sum \mathrm{AC}+\frac{\mathrm{BAC}-\sum \mathrm{EV}}{\mathrm{CPI}}
$$

\section{RESULTS AND DISCUSSIONS}

Earned value management compares the baseline plan to actual schedule and cost performance. Variance analysis as used in EVM compares actual project performance to planned or expected performance. Cost and schedule variances are the most frequently analyzed.

Trend analysis examines project performance over time to determine if performance is improving or deteriorating. Graphical analysis techniques are valuable for understanding performance to date and for comparison to future performance goals in the form of BAC versus EAC and completion dates. Any relationships that result in parametric estimates or analogous estimates involve the use of project characteristics (parameters) to develop mathematical models to predict total project costs. Such models can 
be simple (e.g., residential home construction is based on a certain cost per square foot of space) or complex (e.g., one model of software development costing uses multiple separate adjustment factors, each of which has numerous points within it.

The expenditure of funds should be reconciled with any funding limits on the commitment of funds for this project. T-1, T-3 \& T-5 are over budget and behind schedule and T-2 and T-4 are under budget and ahead of schedule (good performance) [Figure 2].

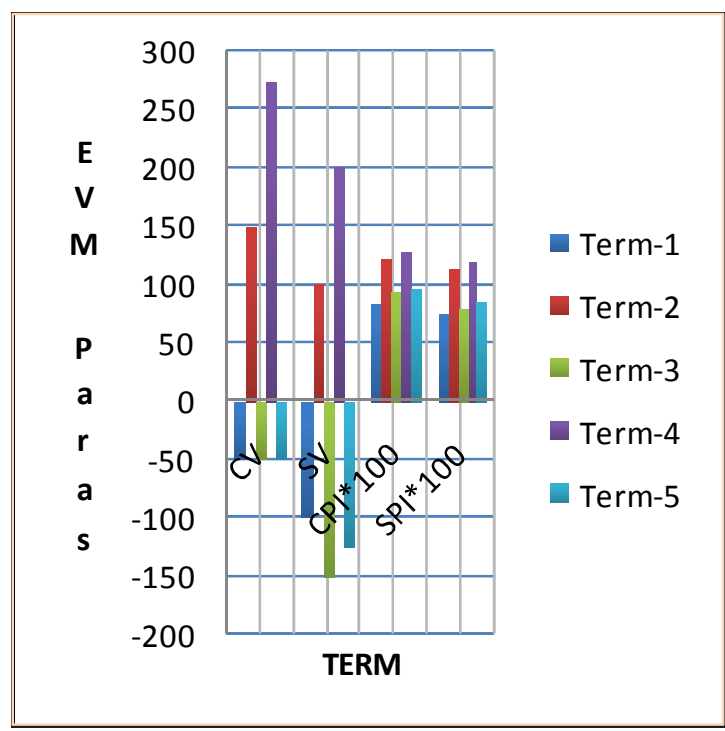

Figure 2. Decision making Parameters for Project Manager.

A variance between the funding limits and the planned expenditures will sometimes necessitate the rescheduling of work to level out the rate of expenditures. This can be accomplished by placing imposed date constraints for work into the project schedule and earned value [Table 1]. Any basic assumptions dealing with the inclusion or exclusion of indirect costs in the project budget are specimen in the basis of estimates. The cost performance baseline is an authorized time-phased budget at completion (BAC) used to measure, monitor, and control overall cost performance on the project. It is a systematic project management process used to predict variances in projects based on the comparison work performed, work planned and work to be scheduled. EVM is used by General Accounting Office by a memorandum of understanding among Australia, Canada and USA for common cost and schedule management in 1996. It is more popular in NASA, Project Management Institute, Society of Cost Estimating and Analysis, Federal Acquisition Institute, Acquisition Management (UK), Defence Acquisition University.

It is developed as a summation of the approved budgets by time period and is typically displayed in the form of an S-curve [Figure 3]. In the earned value management technique the cost performance baseline
Table 1. Project Parameters

\begin{tabular}{|l|l|l|l|}
\hline Duration & $\begin{array}{l}\text { Actual } \\
\text { Cost } \\
(\mathrm{x} 1000 \text { \$) })\end{array}$ & $\begin{array}{l}\text { Earned } \\
\text { Value } \\
(\mathrm{x} 1000 \$)\end{array}$ & $\begin{array}{l}\text { Planned } \\
\text { Value } \\
(\mathrm{x} 1000 \$)\end{array}$ \\
\hline $\mathrm{T}-1$ & 350 & 300 & 400 \\
\hline $\mathrm{T}-2$ & 650 & 800 & 700 \\
\hline $\mathrm{T}-3$ & 700 & 650 & 800 \\
\hline $\mathrm{T}-4$ & 925 & 1200 & 1000 \\
\hline $\mathrm{T}-5$ & 950 & 900 & 1025 \\
\hline
\end{tabular}

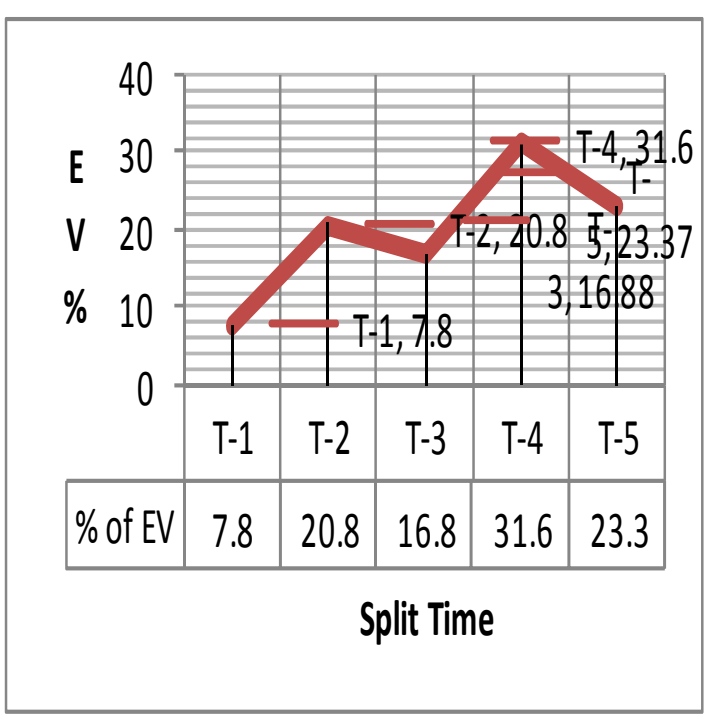

Figure 3. S-Curve for EVM (Cost Vs. Time).

is referred to as the performance measurement baseline (PMB). Formal limitations by period for the expenditure of project funds can be mandated by the organization, by contract or by other entities such as government agencies. These funding constraints are emphasized in the S-curve as project scope statement. S-curve examines the progress of the project, necessity of re-allocation of resources and forecast expenditures in terms of man hours or money. It has significance variables that need analyzing: time, money and scope of the S (known as the route) which indicates the final cost.

\section{CONCLUSIONS}

The basic requirement of an EVM system is to quantify progress using Planning Value and Actual Cost. Project Cost Management should consider the stakeholder requirements for capturing costs. Different stakeholders will measure project costs in different ways and at different times. EVM and Project Cost Management are primarily concerned with the cost of the resources needed to complete project activities. For example, limiting the number of design reviews can reduce the cost of the project but could do so by increasing the customer's operating 
costs. In many organizations, predicting and analyzing the prospective financial performance of the project's product is done outside the project. EVM may address additional processes and numerous general management techniques such as return on investment, discounted cash flow, and investment payback analysis. EVM implementations for large or complex projects describe many more features, such as indicators and forecasts of cost performance (over budget or under budget) and schedule performance (behind schedule or ahead of schedule). EVM prevents scope creep, reduces risk, improves stakeholder communications, forecasts project with profitability and accountability.

\section{RECOMMENDATIONS}

Some recommendations relevant to project cost management include:

i) The cost of an acquired item should be measured when the acquisition decision is made or committed, the order is placed, the item is delivered, or the actual cost is incurred or recorded for project accounting purposes,

(ii) Project Cost Management should also consider the effect of project decisions on the subsequent recurring cost of using, maintaining, and supporting the product, service, or result of the project,

(iii)The cost management planning effort should occur early in project planning and set the framework for each of the cost management processes so that performance of the processes will be efficient and coordinated.

\section{REFERENCES}

1. 100 Great Leadership Ideas: From successful leaders and Managers around the World-Jonathan Gifford, Marshall Cavendish Business, UK, pp. 1-5, 2010.

2. Project Management Institute: A Guide to the Project Management Body of Knowledge (PMBOK Guide) - Fourth Edition, 2008

3. Abba, Wayne, "How Earned Value Got to Prime Time: A Short Look Back and a Glance Ahead". PMI
College of Performance Management (www.pmicpm.org), 2000.

4. Fleming, Quentin; Joel Koppelman (2005). Earned Value Project Management, Project Management Institute.

5. Marshall, Robert A."The contribution of earned value management to project success on contracted efforts: A quantitative statistics approach within the population of experienced practitioners". PMI (www.pmi.org), 2006.

6. Mulcahy Rita, Project Management Professional Examination Prep. $5^{\text {th }}$ Edition, RMC Publications, 2005.

7. Penelope Przekop, Six Sigma for Business Excellence, 61, New York, McGrar Hill, 2003.

8. PMP, Practice Makes Perfect, John A. Estrella, Charles Duncan, Sami Zahran, James L. Haner, Rubin Jen, An imprint of Wiley, USA.

9. Kwak, Y.H., \& Anbari, F.T, Impact of project management of allied disciplines. Newtown Square, PA: Project Management Institute, 2008.

10. Steiner, G.A. (1969), Top management planning, MacMillan, New York, Quoted on p. 481 of D.I. Cleland \& W.R. King (Eds.), Project Management Handbook, $2^{\text {nd }}$ Edition, Van Nostrand Reinhold, New York, 1988.

11. Williams, J. M. 'Transformations in technical communication pedagogy: Engineering, writing, and the ABET engineering criteria 2000: TCQ', Technical Communication Quarterly, 10(2), 149. Retrieved from http://search.proquest.com/docview/215434022, 2001. 12. T. Nakamura, "An Approach to Designing a Project Management Course", 4th Pro MAC International Conference, pp.937-944, 2008.

13. Wayne F.Abba, "Earned Value Management: Reconciling Government and Commercial Practices", 58-63,PM Magazine, January/ February 1997.

14. Basic Concepts of Earned Value Management (EVM), EVM Education Center, 2012 Humphreys \& Associates ( http://www.humphreys-assoc.com)

15. Pisano, Nicholas (1999). "Technical Performance Measurement, Earned Value, and Risk Management: An Integrated Diagnostic Tool for Program Management". Defense Acquisition University Acquisition Research Symposium. 


\section{APPENDIX}

A project is scheduled to last 18 months for its EVM analysis. It has a budget at completion of $\$ 150,000$. The project is $30 \%$ complete, it was supposed to be $35 \%$ complete at this time. Due to force measures (floods and cyclones), it has been delayed and total spent was $\$ 485,230$. Calculate EVM parameters.

\begin{tabular}{|c|c|c|c|c|c|}
\hline Parameter & Formula & $\begin{array}{l}\text { Numerical } \\
\text { Interpretation }\end{array}$ & Parameter & Formula & $\begin{array}{l}\text { Numerical } \\
\text { Interpretation }\end{array}$ \\
\hline $\begin{array}{l}\text { Actual Cost } \\
\text { (AC) }\end{array}$ & $\begin{array}{l}\text { Actual monies } \\
\text { spent }\end{array}$ & $\$ 485,230$ & $\begin{array}{l}\text { Planned } \\
\text { Value (PV) }\end{array}$ & $\begin{array}{l}\mathrm{PV}=\% \text { complete } \\
=35 \% \times \$ 485,230\end{array}$ & $\$ 525,000$ \\
\hline $\begin{array}{l}\text { Earned } \\
\text { Value (EV) }\end{array}$ & $\begin{array}{l}\mathrm{EV}=\% \text { complete } \mathrm{x} \\
\text { budget at } \\
\text { completion } \\
=30 \% \mathrm{x} \$ 150,000\end{array}$ & $\$ 450,000$ & $\begin{array}{l}\text { Cost } \\
\text { Variance }\end{array}$ & $\mathrm{CV}=\mathrm{EV}-\mathrm{AC}$ & $\begin{array}{l}-35,230 \\
\text { (Over budget) }\end{array}$ \\
\hline $\begin{array}{l}\text { Schedule } \\
\text { Variance }\end{array}$ & $\mathrm{SV}=\mathrm{EV}-\mathrm{PV}$ & $\begin{array}{l}-75,000 \\
\text { (Behind Sched.) }\end{array}$ & $\begin{array}{l}\text { Cost } \\
\text { Performance } \\
\text { Index }\end{array}$ & $\mathrm{CPI}=\frac{\mathrm{EV}}{\mathrm{AC}}$ & $\begin{array}{l}0.93 \\
\text { (93 cents/ } \\
\text { dollar) }\end{array}$ \\
\hline $\begin{array}{l}\text { Schedule } \\
\text { Performance } \\
\text { Index (SPI) }\end{array}$ & $\mathrm{SPI}=\frac{\mathrm{EV}}{\mathrm{PV}}$ & $\begin{array}{l}0.83 \\
(83 \% \text { rate } \\
\text { planned })\end{array}$ & $\begin{array}{l}\text { Estimate at } \\
\text { completion }\end{array}$ & $\begin{array}{l}\mathrm{EAC}=\mathrm{AC}+\frac{\mathrm{BAC}-\mathrm{EV}}{\mathrm{CPI}}=\frac{\mathrm{BAd}}{\mathrm{CPI}} \\
=\$ 1500000 / 0.93\end{array}$ & $\begin{array}{l}\$ 1,617,433 \\
\text { (est. project) }\end{array}$ \\
\hline $\begin{array}{l}\text { TCPI at } \\
\text { BAC }\end{array}$ & $\begin{array}{l}\mathrm{TCPI}_{\mathrm{EAC}}=\frac{\mathrm{BAC}-\mathrm{EV}}{\mathrm{EAC}-\mathrm{AC}} \\
=\text { Works } \\
\text { Remaining/ Funds } \\
\text { Remaining }\end{array}$ & 1.03 & $\begin{array}{l}\text { TCPI at } \\
\text { EAC }\end{array}$ & $\begin{array}{l}\mathrm{TCPI}_{\mathrm{EAC}}=\frac{\mathrm{BAC}-\mathrm{EV}}{\mathrm{EAC}-\mathrm{AC}} \\
=\text { Works } \\
\text { Remaining/ } \\
\text { Funds } \\
\text { Remaining }\end{array}$ & 0.93 \\
\hline $\begin{array}{l}\text { Variance at } \\
\text { completion }\end{array}$ & $\begin{array}{l}\text { VAC }=\text { BAC-EAC } \\
=(\$ 1,500,000- \\
\$ 1,617,433)\end{array}$ & $\begin{array}{l}-\$ 117,433 \\
\text { (Over budget at } \\
\text { completion) }\end{array}$ & IEAC & $\begin{array}{l}\sum \mathrm{AC}+\frac{\mathrm{BAC}-\sum \mathrm{EV}}{\mathrm{CPI}} \\
\mathrm{IEAC}=\$ 485230 \\
+(\$ 150,000- \\
\$ 450,000) / 0.93\end{array}$ & $\begin{array}{l}\$ 162,650 \\
\text { (total cost) }\end{array}$ \\
\hline
\end{tabular}

